\title{
History of health technology assessment: A commentary
}

\author{
Sadasivan Sivalal \\ Monash University Sunway Campus
}

I have long felt the need for documentation on the global development-I could probably pin it to the moment I was visiting health technology assessment (HTA) institutions in the United States in 1995, and was looking forward to a trip to the Office of Technology Assessment, only to be told it had just been shut. Instead, I visited the Office of Health Technology Assessment in Washington. In addition, I have observed that some regular attendees of annual meetings of International Society of Technology Assessment in Health Care (ISTAHC) and then Health Technology Assessment International (HTAi), have been slowly dropping out, so that a lot of the history as well as their valuable experiences and expertise have been lost. To be fair, studies have been written about specific HTA institutions, programs, countries, and even regions. Attempts have also been made to chart the history of HTA, but these have, however, fizzled out. Why is this important? Going back to my personal experience, when I first set out to establish HTA in Malaysia, I was plagued with several questions - apart from the obvious one about what HTA really meant, there were others like what organization structure should it have, what should be the work process, how could HTA be used, to name a few. I needed to know what the options were, for example, in coming up with an organizational structure, and to understand these options I would need to look at organizational models in other countriesshould it be a national office with regional offices like the Canadian model, or a fully public agency but not within the department of health, like the Swedish model, or an almost independent agency like the Catalan agency in Barcelona. In the absence of a detailed account with the information I sought, I actually had to physically visit various agencies to study their organizational structure, work process, and application, to hear of the challenges they faced, and to learn from their experiences of what could work and what may not.

So it is wonderful that the International Journal of Technology Assessment in Health Care, specifically Egon Jonsson, has taken the initiative to commission an issue of the Journal on the history of HTA. David Banta deserves spe- cial commendation for taking on this Herculean task, but I cannot think of a more appropriate person for this job, given that Banta has been involved in HTA programs of so many countries around the world. It will probably give them feeling of déjà vu when going through some of the country and regional reports.

HTA has made considerable progress since its introduction more than 30 years ago. As has been repeatedly pointed out, whereas HTA has been well established in the developed countries, less developed countries have not been as successful in this area. The irony of it is it is these economies that need HTA most, in their struggles to maximize the scarce resources that are available to provide healthcare services to their populations. From the United States, it has spread almost all over the world, taking firm root in Europe and Canada. It has moved gradually into Asia and South America, but there are some glaring gaps. There is virtually no HTA in Africa, whereas in countries in the Middle East, there has been some progress.

In a sense, this has also mirrored the spread of research initiatives. A few decades ago, almost all research seemed to be confined to North America and Europe. In a sense, it probably had to do with the state of development of these countries (in comparison to less developed ones), which brought with it a lack of importance of scientific methodology, the need for research evidence in decision making, and indeed the philosophy of the evidence based approach in policy and decision making. It has often struck me that, while in the legal area the use of evidence has been long established, in that previous cases and precedents are used in coming to decisions, no such philosophy exists in the health sector. English law, for example, has been a basis for legal system in many countries, especially in those that were British colonies, such as India, Malaysia, and Australia. If we compare this with the health sector, although health systems have some similarities to the English system in Canada and Australia for instance, countries such as India and Malaysia have evolved totally different systems. So with increasing development, research 
studies began appearing from countries such China, India, and the like.

However, there are some success stories among the developing countries, where HTA programs have been established. Examples of developing countries that have developed HTA programs include Argentina, Brazil, China, Korea, Malaysia, Mexico, Philippines, Thailand, and Taiwan. It can be seen that these are all "emerging" economies. In some, these programs have had a major impact on policy making, such as in Malaysia and the Philippines, for example, whereas in others, either the input may or not be considered or the HTA programs are in the early stages and have yet to create a serious impact.

It is good to note that, in many countries, HTA has been accepted as a precursor to policy making and has been accepted as part of the policy-making process. In many other countries, too, HTA is a part of the health system with ramifications into clinical practice guidelines and evidence-based medicine. In such situations, it is encouraging to see that it has also got the involvement and participation of clinicians. If we consider the factors that dictate the success of an HTA program, the two key areas appear to be utilization of the recommendations of an HTA by policy makers and decision makers, and continued requests for HTA by its users.

On the other hand, countries in South East Asia such as Cambodia, Laos, Myanmar, or South American countries such as Bolivia, Ecuador, or even countries in the Middle East such as Syria and Iraq have no HTA. However, there are countries in that region such as Israel that have an established HTA program, whereas efforts have been started in Iran, Lebanon, and Turkey. As has been mentioned too, Africa has virtually no HTA, except for some efforts in South Africa. What could be some of the reasons for this wide disparity between countries with well-developed HTA systems and those with no efforts toward HTA? Some the factors that can be considered include economic issues, political factors, human resource issues, and a lack of awareness.

The state of the economy has a major influence on when HTA is established. Only when basic needs have been met and the country has a reasonable level of health care do they seem to venture into areas such as research and HTA. It may be important to differentiate between absolute poverty (low and middle income countries) and relative poverty, in which certain members of society are not able to benefit from the same living standards as others.

Another major factor seems to be political systems, be it political instability that would obviously hamper the sustenance of programs such as HTA (Thailand and Indonesia appear to be suitable examples of this), or changes in governance (centralized to a decentralized system). This can be illustrated by considering the example of Finland. During the early 1990s, Finland's gross domestic product (GDP) fell dramatically, and healthcare expenditure rose to 9.4 percent of GDP. However, the economy recovered rapidly, and healthcare expenditure decreased to 7.7 percent. It was at this time too, that the centralized system was changed to decision making being largely decentralized to the municipalities, with reformation of the principles of state subsidies. It was soon after this in 1995, that the Finnish Office for Health Care Technology Assessment (FinOHTA) was set up as a national central body for advancing HTA-related work in Finland (1). A similar situation was seen in England beginning in 1990 when the National Health Service moved away from a centralized administrative structure to more pluralistic arrangements. It was then that HTA gained increasing attention (2). However, whether centralized or decentralized systems promote HTA is open to debate. For example, in Malaysia, the centralized system of health care did facilitate the creating of awareness and training of consultants from hospitals, which in turn facilitated the acceptance of HTA. It goes without saying that other factors such as the doctors opting to continue in the public facilities are more self-sacrificing and service-oriented in comparison to others lured to the private sector by better monetary gain, prestigious positions, and other attractive benefits. This would definitely be a problem in many other developing countries where the private sector is predominant, for example, in many of the richer states in India, where the profitability of the private sector often excludes other considerations. Other factors that have been mentioned include the lack of a proper understanding of many policy makers about the importance of HTA for health care as well as a lack of a critical mass of trained personnel $(3 ; 4)$.

From personal experience again, commitment and dedication coupled with a willingness to fight against all odds are essential for the continued sustenance of an HTA program. Capacity building also has to be carried out almost continuously to ensure availability of suitable personnel to maintain the program.

Finally, the lack of awareness on HTA seems a major problem. It may seem incredible that, even after more than 30 years of existence, HTA is unheard of in many parts of the world. On a personal note, I came to know of HTA only some 15 years ago, and that too after working closely with medical device manufactures, suppliers, and users. This appears to be linked to the users of HTA. It may not be in the interest of manufacturers to promote HTA, which then begs the question, who is responsible for promoting HTA? HTAi and INAHTA appear to be committed to doing this, but the extent to which they are successful remains to be seen. A major constraint seems to be a chicken and egg dilemma-it is only when you become aware of HTA that you get to hear of these organizations, otherwise they are relatively unknown to, for example, many practicing clinicians in some of the countries where HTA does not exist, or even in some countries with HTA. Its predecessor, the International Society of Health Technology Assessment in Health Care (ISTAHC) had made some proactive approaches, but these could not be sustained. The World Health Organization (WHO) and other international organizations such as the World Bank 
have made some efforts. The WHO has carried out many initiatives especially in PAHO (the Pan American Health Organization, the WHO for the Americas) and from the Geneva office, but these efforts have not borne fruit as much as they should have. The European Union has been quite successful in promoting HTA among its member countries. Recently, the International Society of Pharmacoeconomics and Outcomes Research (ISPOR) has stimulated interest in this area among its members.

A major obstacle seems to be funding. Major financial institutions may not see benefits in funding such initiatives. Organizations funding research have indicated some interest in the past, but many seem to be constrained by the fact that HTA has never been claimed to be just research, or even fit into any of the accepted research categories. Is it then a social responsibility to ensure that developing economies, for example, set up HTA programs? In Asia, we set up an Asian HTA Network, but the major obstacle we came up against very soon was funding. Who could we approach for funding? Most agencies involved in this field (or related fields) had practically no budget for this sort of initiative. Others indicated that we need to show some outcomes of the network, but then we had barely started, and needed funds to progress. Eventually, we got some funds from research agencies by convincing them that HTA was also a form of research!

I have long believed that HTA appears to be a sort of crusade (if I could be permitted to use the word devoid of any religious implications) where the "believers" of HTA set out on these long and difficult journeys and engage in often difficult "battles" and overcome all sort of obstacles and "enemies" in their efforts to "convert" people into believing in HTA, and subsequently, practicing and implementing HTA.

\section{CONTACT INFORMATION}

Sadasivan Sivalal, MBBS, PGDHHSA (sivalal@hotmail. com), Senior Lecturer, School of Medicine \& Health Sciences, Monash University Sunway Campus, Jalan Lagoon Selatan, 56150 Bandar Sunway, Selangor, Malaysia

\section{REFERENCES}

1. Läubli M, Brunold H. Effectiveness of disease prevention and health promotion activities and interventions. Briefing paper. Berne: Swiss Federal Office of Public Health; 2005.

2. Lauslahti K, Roine R, Semberg V, et al. Health technology assessment in Finland. Int J Technol Assess Health Care. 2000;16:382-399.

3. Pan-American Health Organization. Health in the summit process. 2000. http://www.cumbre-americas.org/Miami\% 20Summit/Health.htm.

4. Woolf SH, Henshall C. Health technology assessment in the United Kingdom. Int J Technol Assess Health Care. 2000;16:591-625. 